\title{
Competências empreendedoras e processos de aprendizagem empreendedora: modelo conceitual de pesquisa $^{1}$
}

\author{
Entrepreneurial competencies and processes of entrepreneurial learning: a conceptual \\ research model
}

\author{
Marcia Aparecida Zampier ${ }^{2}$ \\ Adriana Roseli Wünsch Takahashi ${ }^{3}$
}

\section{Resumo}

Ao constatar que os empreendedores são indivíduos com características inovadoras, proativas e com facilidade em identificar novas oportunidades, surge a necessidade de entender como eles desenvolvem tais competências. Visitando a literatura percebe-se que existem evidências da inter-relação entre os processos de desenvolvimento de competências empreendedoras e de aprendizagem empreendedora, que os sustentam. Assim, torna-se imprescindível compreender como ocorrem esses processos. Dessa forma, o objetivo do presente estudo é contribuir para o avanço na literatura de empreendedorismo, apresentando um modelo conceitual de pesquisa que integra modelos de competências empreendedoras e de processos de aprendizagem empreendedora. Este artigo, de cunho teórico, resulta de extensa pesquisa bibliográfica e apresenta os resultados obtidos até então, uma vez que pesquisas empíricas para sua validação estão em processo.

Palavras-chave: Empreendedores. Competências empreendedoras. Aprendizagem empreendedora. Pequenas empresas.

\begin{abstract}
Knowing that entrepreneurs are individuals with innovative and proactive characteristics and an eye for identifying new opportunities, the need to understand how they develop these competenciesarises. Reviewing the literature, one can see evidence of inter-relationship competencies in the development processes of entrepreneurial competenciesand entrepreneurial learning that support them. Therefore, it is essential to understand how these processes occur. Therefore, this study aims to make a contribution to improve entrepreneurship literature, presenting a conceptual
\end{abstract}

Artigo submetido em 22 de março de 2010 e aceito para publicação em 19 de abril de 2011.

1 Uma versão preliminar deste trabalho foi apresentada no XI Colóquio Internacional sobre Poder Local: Desenvolvimento e Gestão Social de Territórios, 2009, Salvador/BA. Realizado pela Escola de Administração da UFBA entre os dias14 e 16 de dezembro de 2009, com publicação em anais.

${ }^{2}$

Mestre em Administração pela Universidade Federal do Paraná; Professora da Universidade Estadual do Centro Oeste. Endereço: DEADM/UNICENTRO - Departamento de Administração, Rua Salvatore Renna - Padre Salvador, 875, Santa Cruz, CEP 85015-430, Guarapuava, PR, Brasil. E-mail: marciazampier@gmail.com

3 Doutora em Administração pela Universidade de São Paulo/FEA; Professora da Universidade Federal do Paraná. Endereço: PPGADM/UFPR - Programa de Pós-Graduação em Administração, Av. Pref. Lothario Meissner, 632 - 2ํandar, Jardim Botânico, CEP 80210-270, Curitiba, PR, Brasil. E-mail: adrianarwt@terra.com.br 
research model that integrates models of entrepreneurial competenciesand models of entrepreneurial learning processes. This paper, which is theoretical, results from an extensive literature research and presents the results achieved so far, since empirical research for its validity is still being conducted.

Keywords: Entrepreneurs. Entrepreneurial competencies. Entrepreneurial learning. Small companies.

\section{Introdução}

O empreendedorismo gera impactos na sociedade, na economia e na política, produzindo empregos, gerando rendas, proporcionando crescimento e desenvolvimento (ESPEJO e PREVIDELLI, 2006). De acordo com o Global Entrepreneurship Monitor - GEM 2008 (2009) -, a população brasileira é classificada como uma das mais empreendedoras do mundo, ocupando o $13^{\circ}$ lugar no total de 43 países analisados.

Entretanto, independente da motivação para a criação de novos empreendimentos, é necessário conduzi-los de forma satisfatória para obter sucesso. Para tal, Dias, Nardelli e Vilas Boas (2008) sugerem que os empreendedores precisam contar com ampla variedade de habilidades sociais, as quais envolvem um conjunto de competências que permitem aos indivíduos interagirem uns com os outros. Por isso, Bittencourt (2005) destaca que o desenvolvimento de competências possibilita que as práticas organizacionais sejam direcionadas para uma gestão mais efetiva e propícia à estratégia competitiva, levando-a a vantagem competitiva.

Para desenvolver e ampliar as competências empreendedoras dos indivíduos, Bitencourt (2005) e Freitas e Brandão (2006) salientam a relevância do processo de aprendizagem, afinal, não há desenvolvimento sem aprendizagem, e esta se constitui uma evolução necessária da aquisição de competências. Assim, a aprendizagem é vista como competência e o conhecimento como um recurso, e ambos são fatores-chave para a competitividade econômica e para a participação em várias dimensões da vida social, cultural e política (ANTAL, A. B.; DIERKES, M.; CHILD, J. et al., 2001).

Os empreendedores são comumente identificados em relação a características de inovação, reconhecimento de oportunidades etc. e, para compreender o empreendedorismo nesta acepção, é importante entender como os empreendedores desenvolvem suas competências - para isso, é necessário, também, compreender como ocorre o processo de aprendizagem empreendedora, uma vez que a literatura já tem dado e comprovado evidências suficientes desta inter-relação.

Assim, a análise de competências da perspectiva construtivista remete à associação entre competência e o processo de aprendizagem, tendo em vista que a competência se expressa na ação (LE BOTERF, 2003) em um determinado contexto, com base em conhecimentos e experiências que se acumulam e potencializam os recursos de cada indivíduo (FEUERSCHÜTTE e ALPERSTEDT, 2008). Entretanto, Politis (2005) alerta para o fato de que somente estudar os resultados da aprendizagem com experiências prévias dos empreendedores é de pouca relevância para o campo do empreendedorismo, pois é necessário incluir conceitos e teorias que explorem a aprendizagem empreendedora como um processo experiencial e também observar como esse processo evolui ao longo da carreira empreendedora.

Em virtude disso, o presente estudo considera que a aprendizagem empreendedora é um processo contínuo que facilita o desenvolvimento do conhecimento necessário para começar novos empreendimentos e administrá-los, sendo os conhecimentos advindos da experiência pessoal do empreendedor e utilizados para guiar a escolha de novas experiências (POLITIS, 2005). O aprendizado é alcançado por meio de ações, ou seja, na prática, de forma experiencial (MORRISON e BERGIN-SEERS, 2002), e advém das experiências passadas de sucesso e insucesso, da observação de outros empreendedores e de outras fontes de relacionamento (RAE, 2005; MAN, 2006; LÉVESQUE, MINNITI e SHEPHERD, 2009). Esta aprendizagem "representa o meio pelo qual se adquire a competência, enquanto a competência representa a manifestação do 
que o indivíduo aprendeu" (FREITAS e BRANDÃO, 2006, p. 100). Neste sentido, torna-se pertinente uma abordagem construtivista, experiencial e situada dos conceitos de competência e aprendizagem empreendedora.

Dessa forma, a contribuição, no presente ensaio teórico, está em apresentar os modelos de análise do processo de aprendizagem empreendedora de Rae (2004) e de Politis (2005) e integrar as teorias de aprendizagem empreendedora (POLITIS, 2005) e competências empreendedoras (MAN e LAU, 2000) por meio de um modelo conceitual de pesquisa. Para tanto, serão abordados os temas: empreendedorismo, competências empreendedoras, aprendizagem empreendedora e a inter-relação entre competências e aprendizagem, ambas empreendedoras.

\section{Empreendedorismo}

Empreendedorismo é "o campo de estudo que procura compreender como as oportunidades que geram novos produtos e serviços são descobertas, criadas e exploradas, por quem e com que consequiências" (VENKATARAMAN, 1997, p. 120).

O empreendedorismo como campo de pesquisa acadêmica vem sendo estudado por diversas áreas das ciências humanas e sociais, como a economia, a psicologia, a sociologia e a administração.

Economistas como Cantillon, Adam Smith e Schumpeter foram os precursores no estudo do empreendedorismo e destacaram a importância do empreendedor para o desenvolvimento econômico da sociedade, voltando-se para os resultados e o impacto dos empreendedores no sistema econômico (FILION, 1999).

A abordagem psicológica, behaviorista ou comportamental, representada por autores como McClelland (1972), procura identificar aspectos característicos dos empreendedores, por acreditar que existem traços de personalidade que são próprios destes indivíduos (KETS de VRIES, 1997).

Segundo Guimarães (2002) e Feuerschütte (2006), a abordagem sociológica leva em consideração o contexto, os grupos sociais, em que os indivíduos estão inseridos e considera que as experiências vividas influenciam a escolha por empreender. O potencial do ambiente para a sustentação do negócio, os processos interpopulacionais e alguns fatores institucionais são considerados como elementos da sociedade que intensificam ou dificultam a criação de novas empresas (ALDRICH e MARTINEZ, 2001).

Ferreira, Gimenez e Ramos (2005, p. 3) comentam sobre a mais recente abordagem, intitulada de construtivista, e representada por "Carland, Carland e Hoy (1992); Solymosy e Hisrich (2000) e Inácio Junior e Gimenez (2003)". Essa abordagem trata do empreendedor em uma perspectiva multidimensional, levando em consideração traços individuais, características do empreendimento e fatores ambientais e econômicos.

Stevenson e Jarillo (1990) relatam, ainda, que os estudos sobre empreendedorismo agrupam-se em três categorias: os que estudam os efeitos dos empreendedores na economia, os que buscam pesquisar as origens comportamentais do empreendedorismo e aqueles focados em como o empreendedor atua.

Portanto, o estudo do empreendedorismo engloba o comportamento individual de identificação e criação de oportunidades, o surgimento e o crescimento da organização, o destaque de um ramo, a iniciativa na formação da equipe, a criação destrutiva salutar e a transformação organizacional (BRUSH et. al., 2003). 
Para o GEM (2008), empreendedorismo é qualquer tentativa, por parte de um indivíduo, de grupos de indivíduos ou de empresas já estabelecidas, de criação de um novo negócio ou novo empreendimento, como, por exemplo, uma atividade autônoma, uma nova empresa ou a expansão de um empreendimento existente.

Segundo Baron e Shane (2007), o empreendedorismo é definido como processo que se move por fases distintas, mas intimamente relacionadas, quais sejam: reconhecimento de uma oportunidade; decisão de ir em frente e reunir os recursos iniciais; lançamento de um novo empreendimento; construção do sucesso e aproveitamento das recompensas. O empreendedorismo ocorre, portanto, quando quatro condições básicas são alcançadas: a) motivação frente às tarefas; b) acesso ao conhecimento (know-how); c) expectativa de ganho pessoal; e d) suporte do ambiente (BULL e WILLARD, 1993).

Central aos estudos de empreendedorismo é o próprio empreendedor, tendo em vista que é o coração do empreendimento (MORRISON, 1998). Schein (1985, p. 30) argumenta que o empreendedorismo está relacionado "à criatividade e à propensão de criar algo novo, envolvendo a motivação para superar obstáculos, propensão por aceitar riscos e desejo de elevação pessoal em qualquer objetivo a ser alcançado". O empreendedorismo envolve a pessoa do empreendedor e de uma oportunidade lucrativa, na qual ele é o responsável tanto pela identificação como pela decisão de exploração de uma dada oportunidade (SHANE e VENKATARAMAN, 2000).

Filion (1999, p. 7) destaca que a "essência do empreendedorismo está na percepção e no aproveitamento das novas oportunidades no âmbito dos negócios". Já Morrison (1998) observa que, no coração dos empreendimentos, estão os empreendedores, persistentes em sua busca por oportunidades e esforçados em conseguir os recursos necessários. Para ela, a essência do empreendedorismo é a promoção das mudanças, por intermédio do processo de inovação.

Para Schumpeter (1982), empreendedor é aquele que desestabiliza a ordem econômica existente pela introdução de novos produtos e serviços, por criar novas formas de organização ou por explorar novos recursos materiais. Por sua vez, Gartner (1989) define o empreendedor como um indivíduo que: a) tem comportamento inovador para introduzir novos métodos de produção, ou novos equipamentos, para abrir novos mercados, para reorganizar a indústria e/ou para criar novos recursos de suprimentos; b) emprega práticas estratégicas em seu negócio; e c) tem como propósito o lucro e o crescimento.

De acordo com Hisrich e Peters (1998) apud Pereira (2007, p. 25), o empreendedor é aquele que "exerce atividades de sustentação do negócio": "A identificação de uma oportunidade faz com que o produto ou serviço atenda a uma necessidade do mercado. A captação de recursos permite que o negócio se sustente financeiramente. A construção da empresa e a comercialização remuneram o capital investido, e a interação com os principais interessados pela organização permite que ela consolide sua atuação".

Weber (1989) vê os empreendedores como inovadores, pessoas independentes, cujo papel de liderança nos negócios infere uma fonte de autoridade formal. Filion (1999, p. 19) o define como "uma pessoa criativa, marcada pela capacidade de estabelecer e atingir objetivos e que mantém alto nível de consciência do ambiente em que vive, usando-a para detectar oportunidades de negócios". Este conceito de Filion é adotado no presente estudo, sendo o empreendedor aquele que cria um novo negócio ou novo empreendimento, expande um empreendimento existente (GEM, 2008) ou, ainda, aquele que exerce atividades de sustentação do negócio (PEREIRA, 2007).

O empreendedor, para Degen (1989), além de profundo conhecimento técnico sobre o produto que pretende oferecer e sobre o mercado em que pretende atuar, formaliza estratégias e faz uso de ferramentas de planejamento e controle que lhe proporcionam uma visão sobre a viabilidade ou não de seus empreendimentos. Além disso, tem necessidade de realizar coisas novas, pondo em prática ideias próprias, assumir riscos e estar presente em todas as atividades da empresa. Afinal, o empreendedor é aquele que não se cansa de observar os negócios na constante procura por novas oportunidades. Por qualquer lugar que passe, o empreendedor estará sempre tentando enxergar aquilo que ainda não foi visto, seja no caminho de 
casa, do trabalho, nas compras, nas férias, lendo revistas, jornais ou vendo televisão. Ao identificar uma oportunidade, o empreendedor em potencial coleta o máximo de informações possível sobre o negócio que pretende desenvolver (DEGEN, 1989).

Percebe-se, então, que os empreendedores possuem um bom conhecimento do mercado e dos consumidores e certo grau de competência técnica em seu campo. Entretanto, Ravasi e Turati (2005) alertam que, para realizar suas ideias, é necessário, ainda, ter recursos financeiros, habilidades e competências, que podem ser obtidas na área industrial, comercial e por meio de pesquisas com sócios, consultores, designers etc.

Como não existe um único tipo de empreendedor, não é possível encerrá-lo em um modelo padrão. No entanto, Dornelas (2007) destaca vários tipos de empreendedores, entre eles: a) empreendedor nato (mitológico); b) aquele que aprende (inesperado); c) serial (cria novos negócios); d) corporativo; e) social; f) empreendedor por necessidade; g) herdeiro; e h) normal (planejado).

O perfil do empreendedor traçado por Schumpeter (1982) descreve um indivíduo que possui o sonho e a vontade de fundar um império pessoal, a vontade de conquistar; o impulso de lutar, de se mostrar superior aos outros, de ser bem sucedido, não tanto pelos frutos do sucesso, mas pelo sucesso em si; a alegria de criar e realizar coisas ou simplesmente de empregar a própria energia e engenho; um tipo que procura a dificuldade, que se transforma para tornar possível a transformação, que se deleita com novos empreendimentos, e para quem o ganho pecuniário é, de fato, a expressão consumada do sucesso. Esse tipo de personalidade, para o autor, seria "inato" ao indivíduo.

Filion (1999) relata algumas características dos empreendedores, como, por exemplo: a) têm sonhos realistas, ou visões, com cuja realização estão comprometidos; b) gastam tempo imaginando aonde querem chegar e como chegar; c) delegam e treinam seus empregados para lidar com o inesperado.

Dornelas (2007) elaborou uma nova relação das características dos empreendedores de sucesso, a qual contempla: ser visionário; saber tomar decisões; fazer a diferença e explorar ao máximo as oportunidades; ser determinado, dinâmico, dedicado, otimista e apaixonado pelo que faz; ser independente e construir seu próprio destino; ficar rico; ser organizado, líder, formador de equipe e bem relacionado; possuir conhecimento; assumir riscos calculados, criar valor para a sociedade e planejar muito.

Tantas características necessárias ao empreendedor de sucesso geram um questionamento relacionado ao seu desenvolvimento: se ele nasce com estas características ou se as aprende com o tempo. Morrison (1998) mostra que existe grande debate a respeito, com diferentes considerações e perspectivas. Em uma das abordagens, acredita-se que a característica empreendedora é nata, isto é, pressupõe que a aptidão empreendedora, a habilidade para correr riscos e o desejo de criar um negócio são inerentes ao indivíduo, ou seja, o empreendedor nasce com estas características. Isto pode ser exibido na forma de traços de personalidade que diferenciam os empreendedores dos demais. Alguns exemplos de traços genéticos associados ao empreendedorismo são: autoconfiança, motivação pessoal, criatividade, independência, liderança, propensão a correr riscos (HONMA, 2007).

Outros autores, como Garavan e O'Cinneide (1994), acreditam que o empreendedorismo pode ser cultural e experiencialmente adquirido e que a capacidade empreendedora pode ser influenciada por intervenções da educação e de treinamento. Eles afirmam que a aprendizagem empreendedora envolve o aprender fazendo, explorando problemas de múltiplos pontos de vista, criando redes de relacionamentos, entre outras formas.

Bohnenberger, Schmidt e Freitas (2007) concordam com Mathews e Moser (1996), Scherer e Adams (1998) e Filion (1999) no que diz respeito à influência da família no perfil empreendedor e, consequentemente, na criação de novas empresas porque, para eles, as pessoas apresentam mais chances de se tornarem empreendedoras se houver um modelo na família ou no seu meio. 
Rae (2006) defende que o desenvolvimento de conhecimentos e habilidades sobre e para o empreendedorismo, ou seja, a arte da prática empreendedora é aprendida somente no ambiente de negócio pela intuição, prática e experiência social, e mais do que no ambiente educacional. Mueller e Thomas (2000) relatam que muitos educadores trabalham com a filosofia de que os empreendedores não são natos, mas se formam. Esta visão indica claramente que o empreendedorismo pode ser ensinado e que a autopercepção individual e o potencial empreendedor podem ser melhorados. Kiggundu (2002) acredita, inclusive, que a educação e o treinamento empreendedor podem ser visualizados pela perspectiva de desenvolvimento de competências empreendedoras e, tendo em vista a sua natureza dinâmica, considera importante desenvolver programas educacionais específicos para empreendedores. Dornelas (2008) considera como mito o fato de empreendedores serem natos e nascerem para o sucesso, pois é com o passar dos anos que eles acumulam experiências, habilidades relevantes, contatos e capacidade de ter visão e perseguir oportunidades.

Assim, partindo da literatura consultada e dos conceitos aqui apresentados, segundo os quais o conceito de empreendedor está relacionado às competências gerenciais (LONG, 1983), ou seja, de que o empreendedor é aquele que precisa saber (conhecer), saber fazer e saber agir (SWIERINGA e WIERDSMA, 1992; LE BOTERF, 2003) para enfrentar o mundo globalizado e informacional (DEMO, 1994) e para identificar oportunidades (MAN e LAU, 2000; POLITIS, 2005; COOLEY, 1990; RAE, 2005), cabe avançar, então, para o conceito de competências empreendedoras.

\section{Competências empreendedoras}

Segundo Mamede e Moreira (2005, p. 4), "a competência empreendedora pode ser tratada tanto como competência do indivíduo, quanto relacionada à prática administrativa, devido às diferentes tarefas que desempenham". Para eles, as ações empreendedoras estão associadas às competências por representarem o senso de identificação de oportunidades, a capacidade de relacionamento em rede, as habilidades conceituais, a capacidade de gestão, a facilidade de leitura, o posicionamento em cenários conjunturais e o comprometimento com interesses individuais e da organização.

Essa junção de competências com ações empreendedoras levou à criação do conceito de competência empreendedora definido por Snell e Lau (1994), o qual consiste em corpo de conhecimento, área ou habilidade, qualidades pessoais ou características, atitudes ou visões, motivações ou direcionamentos que, de diferentes formas, podem contribuir para o pensamento ou ação efetiva do negócio. Para esses autores, a arte de criar e gerenciar um pequeno negócio é relacionada ao plano de vida do empreendedor, aos valores e à sua característica pessoal e isso é refletido na amplitude desta definição.

Antonello (2005) definiu competência empreendedora como um conjunto de conhecimentos, habilidades e atitudes que viabilizam a um indivíduo imprimir sua visão, estratégias e ações na criação de valor (tangíveis ou intangíveis) para a sociedade. Assim, o conceito de competência empreendedora está mais próximo dos conceitos de competências individuais, muito embora a primeira já tenha, na literatura, um corpo teórico próprio.

Optou-se por considerar, neste estudo, competência empreendedora como um corpo de conhecimento, área ou habilidade, qualidades pessoais ou características, atitudes ou visões, motivações ou direcionamentos que, de diferentes formas, podem contribuir para o pensamento ou ação efetiva do negócio (SNELL e LAU, 1994) e que permite a um indivíduo imprimir ações, estratégias e sua visão na criação de valor, tangível e intangível, para a sociedade (ANTONELLO, 2005).

Dentro do tema de competência empreendedora, alguns autores têm se preocupado em criar tipologias ou modelos que possibilitem a identificação, por parte dos pesquisadores, de conhecimentos, habilidades, atitudes, enfim, de competências necessárias ao desenvolvimento de suas atividades. Entre eles, dois trabalhos foram identificados na literatura: o de Cooley (1990) e o de Man e Lau (2000). 


\section{Tipologias de competências empreendedoras}

A classificação de Cooley (1990), voltada para os empreendedores, foi revista e adaptada do modelo de competências de McClelland e contém uma lista com 10 competências empreendedoras, a saber: busca de oportunidade e iniciativa; persistência; comprometimento; exigência de qualidade e eficiência; assunção de riscos calculados; estabelecimento de metas; busca de informações; planejamento e monitoramento sistemáticos; persuasão e rede de contatos; independência e autoconfiança.

Morales (2004) utilizou essa tipologia para fazer um estudo sobre competências, buscando medir o grau de relação entre as competências empreendedoras e os tipos psicológicos junguianos. A pesquisa foi feita no estado de Santa Catarina com 82 empreendedores. As características comportamentais empreendedoras predominantes foram: a) busca de informações; b) persuasão e redes de contato; e c) persistência. Por fim, observou-se baixa correlação entre as características empreendedoras e os traços psicológicos.

Para Man e Lau (2000), a competitividade na micro e pequena empresa (MPE) é fortemente influenciada pelas competências do empreendedor. Partindo deste pressuposto, esses autores realizaram diversos estudos empíricos entre 1993 e 1999 que resultaram em uma categorização de competências em seis áreas distintas descritas a seguir.

Competências de oportunidade: estão relacionadas à identificação, avaliação e busca de oportunidades de negócios. De acordo com Paiva Jr., Leão e Mello (2003, p. 2), "um empreendedor deve estar apto a identificar os cenários favoráveis aos objetivos organizacionais e atuar sobre as potenciais chances de negócios por meio da sua avaliação de modo a transformá-las em situações positivas". Essa capacidade de visualizar o ambiente que antecede e ampara o processo de decisão é fundamental para os empreendedores, que, segundo Filion (1999), têm visões cuja elaboração demanda tempo, comprometimento e imaginação sobre o objetivo a ser perseguido e os caminhos necessários para realizá-lo.

Competências de relacionamento: referem-se aos relacionamentos pessoais do empreendedor (GRANOVETTER, 1985) que podem influenciar na definição do caminho a ser seguido em um determinado negócio, os quais estão classificados em três níveis por Filion (1991): primários (abrangem os contatos familiares e as pessoas mais próximas); secundários (amizades e grupos sociais: clubes, religião, política, trabalho) e terciários (contatos com um campo de interesse; ocorrem através de viagens, cursos, exposições, feiras e congressos).

Competências conceituais: dizem respeito às capacidades de avaliar situações de risco que surgem em decorrência de suas ações em qualquer ambiente, ou seja, o empreendedor tende a correr riscos calculados (DORNELAS, 2007); e também à capacidade de perceber situações por ângulos diferentes e de forma positiva. Assim, a inovação permite a diferenciação e integra a dimensão conceitual da competência empreendedora.

Competências administrativas: envolvem a eficiente alocação de talentos humanos, recursos físicos, financeiros e tecnológicos. Para tanto é preciso que o empreendedor tenha a capacidade de planejar, organizar, comandar, motivar, delegar e controlar, enfim, de administrar o empreendimento e seus funcionários (MAN e LAU, 2000).

Competências estratégicas: vinculam-se à escolha e implementação das estratégias do empreendimento, nas quais os empreendedores visualizam panoramas de longo prazo e objetivos de médio e curto prazos alcançáveis e realistas, além de elaborar estimativas de viabilidade financeira e de mecanismos de controle dos seus resultados (MAN e LAU, 2000).

Competências de comprometimento: demandam a habilidade de manter a dedicação do dirigente ao negócio, principalmente em situações adversas, além de demonstrar a dedicação do empreendedor e do seu trabalho árduo, participando de tudo o que acontece na organização, mesmo que em detrimento de sua vida pessoal. 
Esta competência está relacionada com a capacidade que o empreendedor tem de recomeçar a atividade empresarial, mesmo após situações de insucesso, ou, então, com a disposição de não abandonar o negócio, mesmo quando ocorrem crises setoriais ou na economia (MAN e LAU, 2000).

Várias pesquisas foram realizadas utilizando especificamente a tipologia de competências empreendedoras de Man e Lau (2000), como por exemplo: a) Paiva Jr., Leão e Mello (2003) pesquisaram dirigentes de empresas brasileiras de médio e grande porte que atuam em serviços da nova economia, sediadas no eixo Rio-São Paulo; b) Mamede e Moreira (2005) entrevistaram dois empreendedores do ramo hoteleiro de Fortaleza, sendo um cearense e outro português; c) Fonseca, Mello, Paiva Jr. et al. (2006) pesquisaram o empreendedor Miguel Abuhab, fundador de uma das maiores empresas de Tecnologia da Informação do Brasil, DATASUL, considerado duas vezes o melhor empreendedor do ano e amplamente reconhecido como um empreendedor de sucesso; d) Paiva Jr., Guerra, Oliveira, et al. (2006) entrevistaram dirigentes de duas empresas graduadas pelo sistema de incubação que atuam na Região Metropolitana do Recife; e) Honma (2007) analisou as competências empreendedoras dos proprietários de seis hotéis de pequeno e médio porte em Curitiba/PR; f) Dias, Nardelli e Vilas Boas (2008) identificaram as competências empreendedoras relacionadas aos cinco dirigentes empreendedores ganhadores do prêmio TOP Empresarial 2006, promovido pelo SEBRAE/RJ.

Estes estudos parecem evidenciar que as competências empreendedoras abrangem predominantemente os fatores oportunidade e gestão. Tal ênfase parece convergir para os principais temas de pesquisa em empreendedorismo, que têm atraído a atenção dos pesquisadores nas últimas décadas em face das características particulares dos empreendedores e das suas dificuldades na criação e desenvolvimento de novas empresas. Assim, constatou-se que o desenvolvimento das competências, embora diferenciadas nos diversos setores, está associado a um processo de aprendizagem (BITENCOURT, 2005; FEUERSCHÜTTE e GODOI, 2007; BARINI FILHO, 2008).

Competências e aprendizagem são, portanto, abordagens complementares, pois, para que haja desenvolvimento da aprendizagem, é preciso repensar as competências das pessoas, ao mesmo tempo em que o desenvolvimento das competências é baseado num processo contínuo de aprendizagem, criando um círculo vicioso (BITENCOURT, 2005). Afinal, não há desenvolvimento sem aprendizagem, constituindo-se esta um processo necessário para a aquisição de competências. Portanto, a mesma ênfase encontrada no potencial explicativo dos estudos que conectam as categorias de aprendizagem e competências na literatura de nível individual e organizacional tem sido dada na literatura de empreendedorismo, ainda que de forma incipiente.

\section{Aprendizagem empreendedora}

A aprendizagem empreendedora consiste em um processo social contínuo de aprendizagem individual em que as pessoas aprendem com suas próprias experiências e com as dos outros, desenvolvendo as próprias teorias, as quais são aplicadas, adaptadas e aprendidas por outros, em virtude do sucesso que proporcionam (RAE e CARSWELL, 2000).

Minniti e Bygrave (2001, p. 7) consideram a aprendizagem empreendedora "um processo que envolve repetição e experimentação que aumentam a confiança do empreendedor em certas ações e desenvolvem o conteúdo de seu estoque de conhecimentos". Taylor e Thorpe (2004) a descrevem como um processo de coparticipação que envolve reflexão, teoria, experiência e ação e é dependente de fatores sociais, históricos e culturais.

$\mathrm{Na}$ visão de Rae (2005), o termo 'aprendizagem empreendedora' significa reconhecer e agir nas oportunidades, interagindo socialmente para iniciar, organizar e administrar novos empreendimentos. E, para Cope (2005), é um processo dinâmico de consciência, reflexão, associação e aplicação que envolve a transformação de experiência e conhecimento em aprendizagem funcional. 
Já para Politis (2005, p. 401), trata-se de "um processo contínuo que facilita o desenvolvimento do conhecimento necessário para ter eficácia na criação e gestão de novos negócios". Assim, pode-se dizer que aprendizagem empreendedora é o processo pelo qual as pessoas adquirem, assimilam e organizam os conhecimentos recentemente formados com estruturas pré-existentes (MINNITI e BYGRAVE, 2001; CORBETT, 2005; HARRISON e LEITCH, 2005).

De acordo com Man (2006), a aprendizagem empreendedora é estudada de diversos enfoques: experiencial, cognitiva e networking. A abordagem experiencial é baseada no modelo de aprendizagem de Kolb (1984), que sugere que a aprendizagem é um processo pelo qual os conceitos são derivados e continuamente modificados pela experiência e pela reflexão do empreendedor. $\mathrm{O}$ foco da abordagem cognitiva é de que a aprendizagem empreendedora é um processo mental de aquisição, estoque e uso do conhecimento empreendedor em longo prazo. Esse processo é afetado por fatores emocionais, motivacionais, de atitude e de personalidade, como motivação, determinação e confiança. Já para a abordagem de networking, as habilidades e os conhecimentos dos empreendedores de MPE's são adquiridos por meio de suas redes de relacionamento, incluindo clientes, fornecedores, bancos, educação universitária, profissionais de outras empresas, parentes, amigos e mentores.

Rae e Carswell (2000) relatam que os empreendedores aprendem por meio da experiência direta, das práticas, dos sucessos e dos insucessos, assim como pelos relacionamentos com outras pessoas. Portanto, a aprendizagem ocorre com a participação de indivíduos em atividades sociais, levando-se em consideração que o conhecimento é produzido conjuntamente com as situações em que as atividades são realizadas, tendo sempre um local e um tempo de ocorrência específicos (GHERARDI e NICOLINI, 1998). Dessa forma, a aprendizagem empreendedora é dirigida por necessidades práticas (MAN, 2006), ou seja, os empresários aprendem com as experiências passadas, quer seja com os seus sucessos ou com seus fracassos anteriores, pois os sucessos lhes proporcionam segurança, enquanto os fracassos os estimulam a procurar novas possibilidades e experimentar novas técnicas de aprendizagem.

Lévesque, Minniti e Shepherd (2009) relatam que os empreendedores que pretendem iniciar um novo negócio podem aprender observando outros empreendedores. Já no que diz respeito à aprendizagem dos empreendedores estabelecidos, isto é, aqueles que ultrapassaram a barreira dos primeiros 42 meses de existência do seu negócio (GEM 2008, 2009), a aprendizagem pode ocorrer de diversas formas, nas quais as crises e os incidentes críticos são extremamente importantes tanto para o empreendedor, pois proporcionam novos aprendizados, tendo em vista que exigem reflexão e ação, quanto para o entendimento do processo de aprendizagem empreendedora (PRIYANTO e SANDJOJO, 2005).

Os proprietários e gestores dos pequenos negócios aprendem informalmente com consumidores, fornecedores, empregados, associações, competidores e outros empreendedores (HARRISON e LEITCH, 2005), aprendem fazendo, explorando, experimentando, trabalhando, copiando e resolvendo problemas (PITTAWAY e COPE, 2007). Portanto, a aprendizagem experiencial é grande em pequenos negócios e o local de trabalho representa um poderoso e rico laboratório de aprendizagem (MORRISON e BERGINSEERS, 2002).

Com o objetivo de entender o processo de aprendizagem empreendedora, alguns autores (MORAES e HOELTGEBAUM, 2003; RAE, 2004; POLITIS, 2005) elaboraram modelos de análise do processo de aprendizagem empreendedora, os quais serão resumidamente apresentados em seguida.

\section{Modelos de aprendizagem empreendedora}

A primeira referência para se analisar o processo de aprendizagem dos empreendedores é a de Moraes e Hoeltgebaum (2003, p. 15), na qual as autoras, partindo do pressuposto de que "o processo de formação do empreendedor deve considerar a etapa do ciclo de vida da organização", relatam que, para compreender 
como os empreendedores de fato aprendem, é preciso entender, além de como eles se tornam empreendedores, como gerenciam o seu próprio negócio e como atuam estrategicamente. Portanto, a análise envolve a identificação de oportunidade e a administração da empresa criada. Este modelo para análise do processo de aprendizagem de empreendedores pode ser observado no Quadro 1.

Quadro 1

Modelo para investigação e análise do processo de aprendizagem empreendedora

\begin{tabular}{|l|l|}
\hline $\begin{array}{l}\text { Etapas da aprendizagem do } \\
\text { empreendedor }\end{array}$ & Aspectos explorados em cada etapa \\
\hline $\begin{array}{l}\text { Aprendizagem para o } \\
\text { empreender }\end{array}$ & $\begin{array}{l}\text { Como o empreendedor adquiriu as habilidades que lhe possibilitaram tornar- } \\
\text { se um empreendedor, ou seja, abrir seu próprio negócio. }\end{array}$ \\
\hline Aprendizagem gerencial & Como o empreendedor aprendeu a gerenciar o seu próprio negócio. \\
\hline Aprendizagem estratégica & $\begin{array}{l}\text { Como o empreendedor adquiriu conhecimentos, habilidades e atitudes que } \\
\text { lhe possibilitaram agir estrategicamente no seu negócio. }\end{array}$ \\
\hline
\end{tabular}

Fonte: Moraes e Hoeltgebaum (2003, p. 16).

De acordo com Moraes e Hoeltgebaum (2003), esse modelo proposto possibilita uma análise rica e profunda do processo de aprendizagem empreendedora, pois se baseia na ideia de que a aprendizagem deve ser pensada em etapas de acordo com o ciclo de vida em que se encontra a organização do empreendedor. Ele também se baseia na compreensão do processo de aprendizagem gerencial na qual a finalidade do empreendedor consiste em criar um negócio e administrá-lo de modo que cresça e sobreviva no longo prazo, possibilitando desenvolvimento. Esse modelo é importante pelo fato de gerar insights para elaboração de roteiros de entrevistas a serem realizadas pelos pesquisadores junto aos empreendedores. No entanto, ele precisa ser validado pela aplicação em estudos empíricos.

Um segundo modelo para análise de aprendizagem empreendedora identificado na literatura foi o de Rae (2004), que considera o indivíduo dentro do seu contexto social (ver Figura 1) e abrange três dimensões: a) formação pessoal e social; b) aprendizagem contextual; c) empreendimento negociado. Esses temas foram subdivididos em outros subtemas e o modelo foi testado empiricamente em diversos estudos realizados pelo próprio autor. 
Figura 1

\section{Modelo de aprendizagem empreendedora}

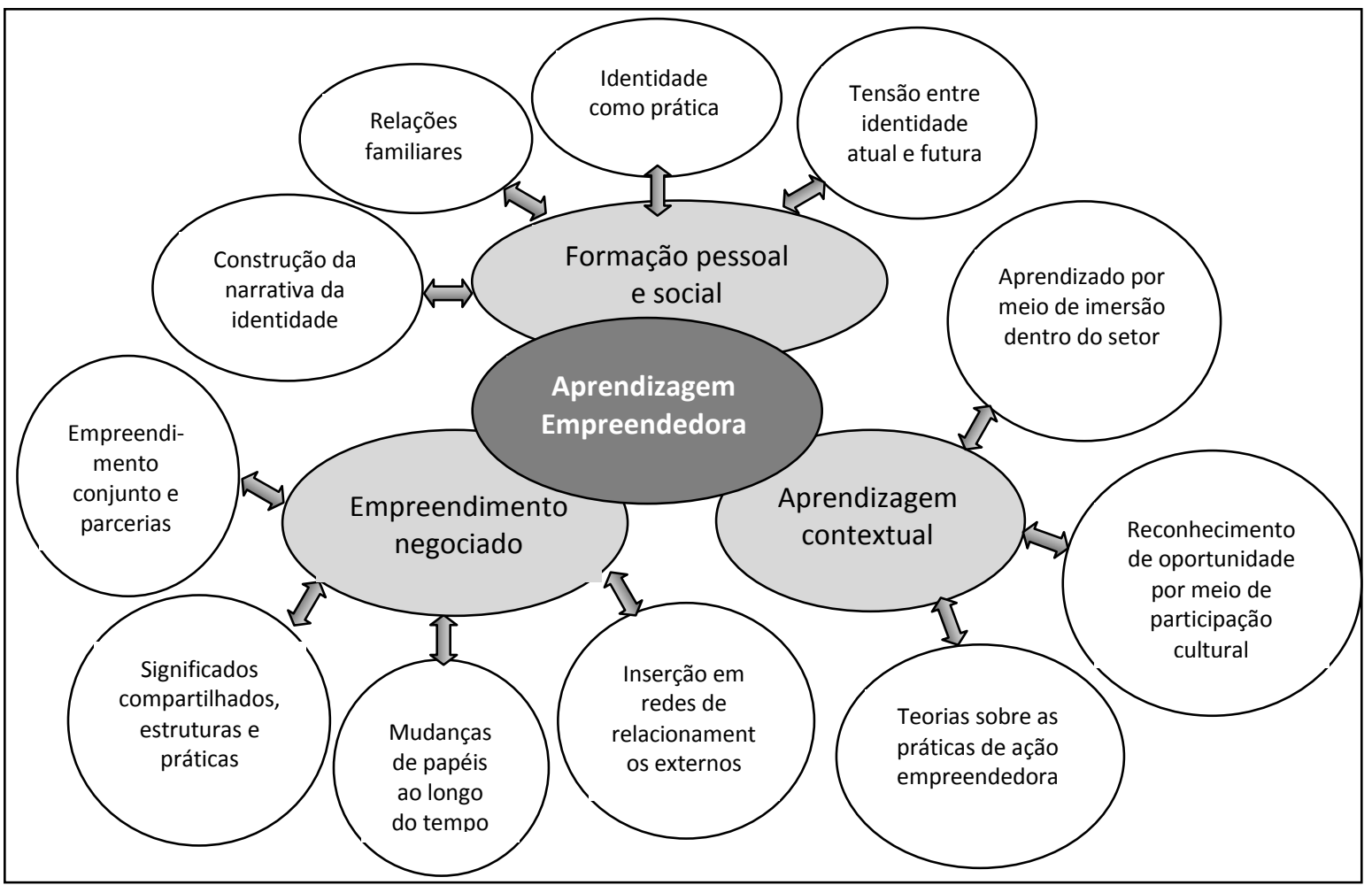

Fonte: Rae (2004, p. 495, tradução dos autores).

De acordo com este modelo, Rae (2004) explora cada uma das três dimensões conforme se descreve a seguir.

Formação pessoal e social: de acordo com Rae (2004), por meio da formação pessoal e social, a pessoa pode desenvolver sua identidade empreendedora, a qual expressa os seus sentidos e futuras aspirações. A formação de identidade empreendedora é influenciada pela sua vida e pelas experiências familiares, pela educação e formação de carreira, além das relações sociais.

Aprendizagem contextual: ocorre quando as pessoas relatam e comparam as suas experiências individuais com as de outras pessoas, criando e compartilhando significados por intermédio de sua participação social e cultural na área de interesse e em outras redes de relacionamentos. Por meio dessas relações sociais e das experiências, as pessoas aprendem intuitivamente e podem desenvolver suas habilidades para reconhecer oportunidades. Assim, a aprendizagem contextual envolve aprender por meio da imersão dentro do setor de interesse e reconhecer oportunidades por meio de participação cultural e teorias sobre as práticas de ação empreendedora, que são descritas como uma ferramenta analítica que habilita a pessoa a ver conexões e criar significados entre aspectos de sua vida e ações práticas.

Empreendimento negociado: as ideias e aspirações dos indivíduos são realizadas mediante um processo negociado de trocas interativas com outras pessoas em relação ao empreendimento, incluindo consumidores, fornecedores, investidores, empregados ou sócios. Este tema inclui quatro subtemas: empreendimento conjunto e parcerias; significados compartilhados, estrutura e práticas; mudanças dos papéis ao longo do tempo; e inserção em redes de relacionamentos externas. 
O terceiro modelo (Figura 2) identificado na literatura de aprendizagem empreendedora é o de Politis (2005), que já foi validado por diversos estudos empíricos e evidencia um processo de transformação de experiência em conhecimento. Esta autora argumenta que a experiência e, em particular, a experiência anterior em criação de negócios, é importante para a aprendizagem empreendedora, pois os conhecimentos advêm dessas experiências e influenciam as escolhas estratégicas feitas pelos empreendedores nos seus novos negócios.

Figura 2

\section{Estrutura conceitual de aprendizagem empreendedora como um processo experiencial}

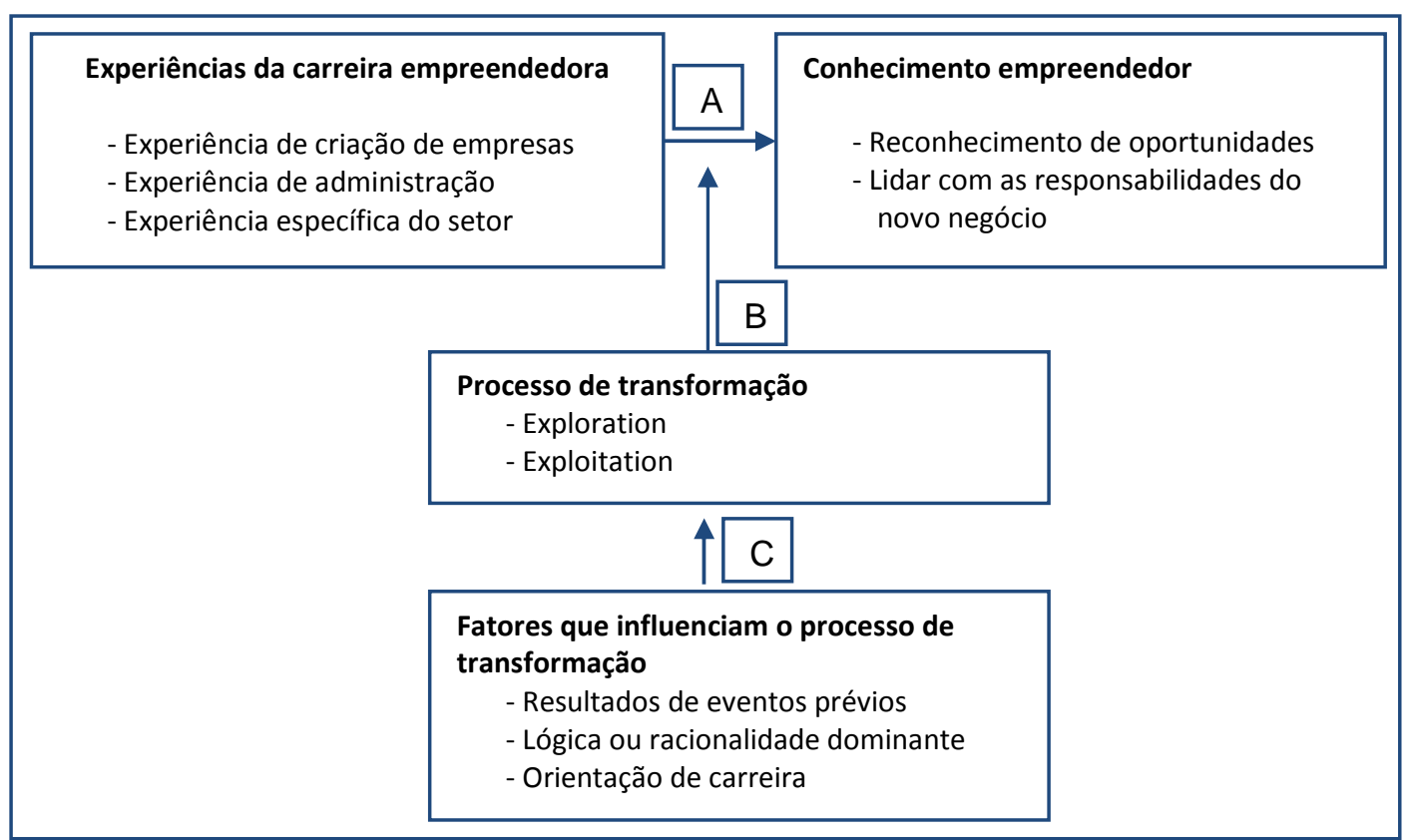

Fonte: Politis (2005, p. 402, tradução dos autores).

O estudo de Politis (2005) se destaca pela contribuição que traz à literatura existente sobre aprendizagem empreendedora, de três formas: a) ao enfatizar o papel da experiência no desenvolvimento do conhecimento empreendedor, integrando teorias da aprendizagem experiencial (KOLB, 1984; MARCH, 1991) ao campo do empreendedorismo; b) ao distinguir entre a experiência de um empreendedor e o conhecimento por ele adquirido; e c) ao desenvolver um enfoque mais dinâmico da aprendizagem empreendedora, ou seja, ao focar no processo intermediário entre as experiências empreendedoras e o desenvolvimento do conhecimento empreendedor e como estes são transformados continuamente. Portanto, o foco do estudo é colocado no processo de transformação das experiências dos empreendedores.

Seguindo a sequência proposta por Politis (2005) para explicar seu modelo conceitual, a primeira categoria a ser considerada é a do conhecimento empreendedor.

Conhecimento empreendedor: quando a aprendizagem é aplicada ao conceito de empreendedorismo, costuma-se descrever o aprendizado como o reconhecimento de uma oportunidade e pela forma de agir ao encontrá-la, além da descoberta de modos de superação dos obstáculos tradicionais na organização e administração de novos negócios, de maneira que as responsabilidades dele oriundas sejam cumpridas.

O conhecimento está estruturado pela prática e pela observação e é resultante do processo de aprendizagem que ocorre ao longo do tempo, sofrendo mudanças e gerando outras no comportamento dos indivíduos 
(LEZANA e TONELLI, 1998). Portanto, as pessoas adquirem conhecimento de três formas: a) pela experiência direta; b) pela observação das ações dos outros e suas consequências e c) pela consulta a fontes como livros, artigos, etc. (HOLCOMB, IRELAND, HOLMES JR. et al., 2009).

Experiências da carreira do empreendedor: a experiência prévia em criação de novos negócios pode prover o empreendedor com insights sobre como desenvolver e financiar novas organizações, produtos ou serviços, como contratar e liderar pessoas e como atrair e manter consumidores (POLITIS, 2005; 2008). Os três tipos de experiências relevantes na carreira dos empreendedores são: experiência em criação de novas empresas, experiência em gestão e experiência no ramo específico em que se pretende atuar. Cada um desses tipos facilita a aquisição de conhecimento que pode ajudar a resolver problemas similares no futuro. No entanto, o modo como essas experiências são transformadas em conhecimentos depende do processo de transformação predominante do empreendedor.

Processo de transformação de aprendizagem empreendedora: Politis (2005) utiliza o modelo de Kolb (1984), que considera a aprendizagem como um processo de transformação de experiências, as quais são continuamente criadas e recriadas. No entanto, ela argumenta que, quando se estuda o processo de aprendizagem empreendedora, é importante reconhecer que o modelo cíclico de Kolb não é plenamente adequado para entender a complexidade e as incertezas dos empreendedores, tendo em vista que o processo de aprendizagem empreendedora não necessariamente segue essa sequência cíclica predeterminada, justificando, assim, a criação do seu modelo e demonstrando o avanço dos seus estudos.

A aprendizagem empreendedora é um processo experiencial no qual a experiência de carreira de um empreendedor é transformada em conhecimento por meio do equilíbrio entre a exploitation do que ele já sabe e da exploration ${ }^{4}$ de novas possibilidades (POLITIS e GABRIELSSON, 2005) e esse conhecimento pode ser usado para guiar as escolhas de novas experiências. Exploitation refere-se à exploração do que já é conhecido, ou seja, de velhas certezas, nas quais os empreendedores podem escolher ações que replicam seus conhecimentos existentes com o objetivo de obter vantagens, reduzir custos e maximizar benefícios, incluindo refinamento, rotina e implementação de conhecimento, execução, produção e escolhas (MARCH, 1991); exploration é o meio pelo qual os indivíduos aprendem com experiências de explorar novas possibilidades, descobertas e inovação (WEICK e WESTLEY, 1996; POLITIS, 2005), que são distintas das anteriores.

Nenhum desses dois modos de transformar experiência em conhecimento é necessariamente melhor que o outro, pois, de acordo com March (1991), os dois são essenciais para sustentar a aprendizagem, sendo necessário, então, manter um equilíbrio entre ambos, visando à prosperidade. Com base nestes conceitos, Politis (2005) afirma que o modo predominante, dos empreendedores, de transformação de experiência em conhecimento pode moderar a relação entre a sua experiência de carreira e o desenvolvimento de conhecimento empreendedor.

Estes processos de transformação de experiência em conhecimento empreendedor são influenciados por determinados fatores, descritos a seguir.

Fatores que influenciam o processo de transformação da experiência em conhecimento: Politis (2005) identificou três fatores que podem auxiliar a compreender o modo predominante pelo qual os empreendedores transformam experiência em conhecimento empreendedor: a) resultados de eventos empreendedores prévios, quer sejam com experiências bem sucedidas ou com insucesso, pois podem ser replicados quando positivos e evitados quando negativos; b) lógica ou racionalidade dominante de um empreendedor. Segundo Sarasvathy (2001) há dois tipos de racionalidade em teorias econômicas: causação e efetuação. O raciocínio causal usa técnicas de análise e estimativa para explorar mercados latentes. Foca no

4 Os termos exploration e exploitation, neste trabalho, foram mantidos em inglês por serem traduzidos pela mesma palavra em português (exploração). O sentido dos termos será discutido posteriormente. 
que deve ser feito de acordo com as metas predeterminadas, os meios possíveis e os resultados imaginados, ou seja, na predição por meio da realização de pesquisas de mercado, projeções financeiras, plano de negócios, entre outros. A causação "envolve a criação de alternativas adicionais para atingir determinadas metas" (SARASVATHY, 2001, p. 2). Já a lógica de efetuação não começa com metas pré-estabelecidas, mas segue metas que emergem com o tempo, de acordo com a imaginação e aspirações do fundador; c) orientação da carreira do empreendedor. Neste último tipo são identificados quatro estilos: linear, especialista, espiral e transitória. A preferência do empreendedor por um desses estilos é baseada em diferentes motivos. Assim, enquanto alguns preferem explorar novas atividades, mudar de campo, de organização e de trabalho, outros preferem a rotina e a especialização (BROUSSEAU et al., 1996 apud POLITIS, 2005; POLITIS e GABRIELSSON, 2006).

Em suma, os três modelos apresentados (MORAES e HOELTGEBAUM, 2003; RAE, 2004; POLITIS, 2005) parecem evidenciar aspectos relevantes para pesquisas em aprendizagem empreendedora, como o processo de identificação de oportunidades e o processo de gestão da organização. Para explorar tais processos, estes autores apresentam consenso na relevância de se utilizar a abordagem de aprendizagem experiencial, baseada na prática, no contexto e na ação, e em investigar o conhecimento obtido. Outro ponto de consenso entre eles parece ser a necessidade de realizar pesquisas ao longo do tempo que privilegiem a história de vida dos empreendedores, suas carreiras e experiências, suas motivações e a sua formação. Estes são aspectos metodológicos a serem considerados em pesquisas sobre o processo de aprendizagem empreendedora.

\section{Competências empreendedoras e aprendizagem empreendedora}

Inicialmente, o estudo focalizou o campo das competências empreendedoras. A pesquisa sobre o conceito de competências, ainda em construção (RUAS, 2005), mostrou que há diversas abordagens possíveis. No entanto, o estudo do tema e dos modelos de competências empreendedoras apontou para sua convergência com os conceitos de competência individual. Num segundo momento, foram levantados os fundamentos que tratam da aprendizagem empreendedora com seus conceitos, abordagens e modelos. Novamente adotou-se, aqui, a abordagem individual de aprendizagem, com ênfase na aprendizagem experiencial. Buscou-se, então, na literatura estudos teóricos e empíricos que abrangessem as duas categorias: competências empreendedoras e aprendizagem empreendedora, a fim de aprofundar a inter-relação entre elas. Foram encontradas (a) diversas pesquisas sobre competências empreendedoras e sobre aprendizagem empreendedora, mas não com as duas juntas como potencial explicativo de uma realidade; e (b) diversas pesquisas nacionais, principalmente sobre aprendizagem empreendedora, que não utilizam os modelos internacionais identificados na literatura. Então, como os conceitos de competências empreendedoras e aprendizagem empreendedora estão em construção e ainda não se tem uma clara exploração de como a inter-relação entre eles está construída, identificou-se a necessidade de trabalhos que explorem com mais profundidade a integração destas duas categorias para estimular e subsidiar novas pesquisas teórico-empíricas, evidenciando a atualidade e a relevância do tema e demonstrando a importância do presente estudo para o avanço da literatura.

Alguns argumentos, entre os autores pesquisados, suportam a conexão entre aprendizagem e competências dos empreendedores, como os citados a seguir.

a) As competências do empreendedor são construídas e se revelam na ação (LE BOTERF, 2003) por meio da reflexão sobre esta e sobre o contexto que envolve o processo empreendedor (FEUERSCHÜTTE e GODOI, 2007).

b) "A competência é um entendimento prático de situações que se apoia em conhecimentos adquiridos e os transforma na medida em que aumenta a diversidade das situações" (ZARIFIAN, 2001, p. 72). Assim, "percebe-se com clareza o vínculo entre experiência, conhecimento e competência" (ZARIFIAN, 2001, p. 152). Entretanto, ao se falar de experiência e de organizar sua aquisição, é 
preciso observar as rotinas e hábitos que um indivíduo deve adquirir. Por isso, subentende-se que, "numa palavra, a aquisição de rotinas e de hábitos presume uma aprendizagem" (ZARIFIAN, 2001, p. 154).

c) A teoria da aprendizagem é usada para explorar como o proprietário de pequeno negócio aprende e consegue sobreviver, tendo em vista que, neste caso, sua habilidade está relacionada com este tipo de negócio (PRIYANTO e SANDJOJO, 2005).

d) Praticamente todos os comportamentos de uma organização, diretos ou indiretos, são influenciados pela aprendizagem. Por exemplo, habilidade dos trabalhadores, comportamento dos gestores, motivação dos assistentes, tudo isso resulta de aprendizagem. Junto com a aplicação de princípios e processos de aprendizagem, o comportamento dos trabalhadores pode ser analisado e gerido visando à sua melhoria (PRIYANTO e SANDJOJO, 2005).

e) Para Priyanto e Sandjojo (2005), a aprendizagem é um fenômeno complexo e dinâmico e consiste no processo de desenvolvimento de habilidades e competências do empreendedor.

As experiências ocupam um lugar de destaque na discussão sobre a formação e o desenvolvimento de competências por meio de experiências passadas e refletidas, assim como pelas conclusões que delas são tiradas (LE BOTERF, 2003; LÉVY-LEBOYER, 2003). Por isso Fleury e Fleury (2004a), Le Boterf (2003) e Zarifian (2001) relatam que o desenvolvimento de competências pressupõe autonomia, iniciativa e responsabilidade do indivíduo, além do querer agir, pois, segundo Le Boterf (2003, p. 154-155), a "competência é inseparável da motivação por estar sempre ligada à situação significativa construída pelo sujeito".

"Cada vez mais um indivíduo constrói sua competência entrando em contato, no seu percurso educativo ou profissional, com uma multiplicidade de fontes de conhecimentos, especialidades e de experiências" (ZARIFIAN, 2001, p. 115). Assim, as competências podem ser edificadas no processo de aprendizagem oferecido pelos cursos de formação educacional ou na própria experiência pessoal, social e profissional, ou seja, por meio de práticas formais e informais (BITENCOURT, 2005), pois "a experiência, a educação, a formação e o posicionamento social orientam o horizonte de expectativas" (LE BOTERF, 2003, p. 138).

Segundo Antonello (2006, p. 215), a aprendizagem designa ao indivíduo e aos grupos a oportunidade de vivenciar ou experimentar algum tipo de situação ou problema, o que implica uma ação. Esta pode estar relacionada à "reflexão antes, durante ou depois do que se vivencia, reportando-se à noção do ciclo de aprendizagem e resultando no desenvolvimento de competências". Por isso, para Feuerschütte e Godoi (2007, p. 13), "a associação entre conhecimentos e experiências, com a produção de novos saberes aplicados a novos contextos, mostra que a competência em ação alavanca o processo de aprendizagem”.

Assim, Antonello (2006, p. 216) salienta que "a aprendizagem experiencial é muito mais do que um simples acumular de experiências", pois a experiência é tida como a "interação de uma pessoa ou coletivo com a situação de trabalho", de modo que nem toda experiência permite diretamente uma aprendizagem. Para ela, a experiência pode, às vezes, promover transformação em decorrência de uma "repetição" ou "impregnação" e não de uma aprendizagem.

Para que a aprendizagem ocorra, é necessário que haja intencionalidade por parte dos indivíduos no ambiente de aprendizagem formal ou nas práticas de trabalho. Assim, a aprendizagem experiencial "pode apresentar-se como um processo a ser empregado na geração e desenvolvimento de competências gerenciais, capacitando os gerentes a fazer frente às novas exigências" (ANTONELLO, 2006, p. 217). 


\section{Modelo conceitual de competências e aprendizagem de empreendedores}

Com a revisão da literatura apresentada foi possível constatar que a aprendizagem experiencial representa um processo utilizado para a geração e desenvolvimento de competências empreendedoras, capacitando os empreendedores a "lidar com as responsabilidades de um novo negócio" (POLITIS, 2005, p. 402).

O modelo de Politis (2005) explicita a ligação com o conceito de competências ao tratar o conhecimento empreendedor como a habilidade de reconhecer oportunidades e de lidar com os desafios e as responsabilidades de um novo negócio. Corresponde, desse modo, às competências empreendedoras do modelo de Man e Lau (2000), destacadas no modelo conceitual apresentado neste estudo, ou seja, as competências de oportunidade e administrativas. Assim, pressupõe-se que a investigação do processo de aprendizagem empreendedora por meio do modelo de Politis (2005) integrado ao modelo de competência empreendedora de Man e Lau (2000) representa uma estrutura com forte potencial explicativo para o desenvolvimento dessas duas competências empreendedoras, conforme se vê na Figura 3.

Portanto, considerando o pressuposto de que competências consistem no resultado do processo de aprendizagem empreendedora e podem ser mais bem compreendidas por meio da análise das experiências e conhecimentos do empreendedor, entende-se que as competências de oportunidade e administrativas (MAN e LAU, 2000) resultam do processo de transformação de experiências da carreira do empreendedor em conhecimento do empreendedor (POLITIS, 2005).

Esse processo de transformação de experiência da carreira em conhecimento pode ocorrer por meio da exploration de novas possibilidades ou da exploitation de velhas certezas empreendedoras, dependendo do estilo e das escolhas dos empreendedores envolvidos nesse processo. É importante destacar também que, independentemente do modo de transformação escolhido pelo empreendedor, haverá fatores que influenciarão esse processo; entre os quais Politis (2005) destaca os resultados obtidos anteriormente pelo empreendedor, seus sucessos ou insucessos, sua lógica dominante e sua orientação de carreira. 
Figura 3

Modelo conceitual de pesquisa

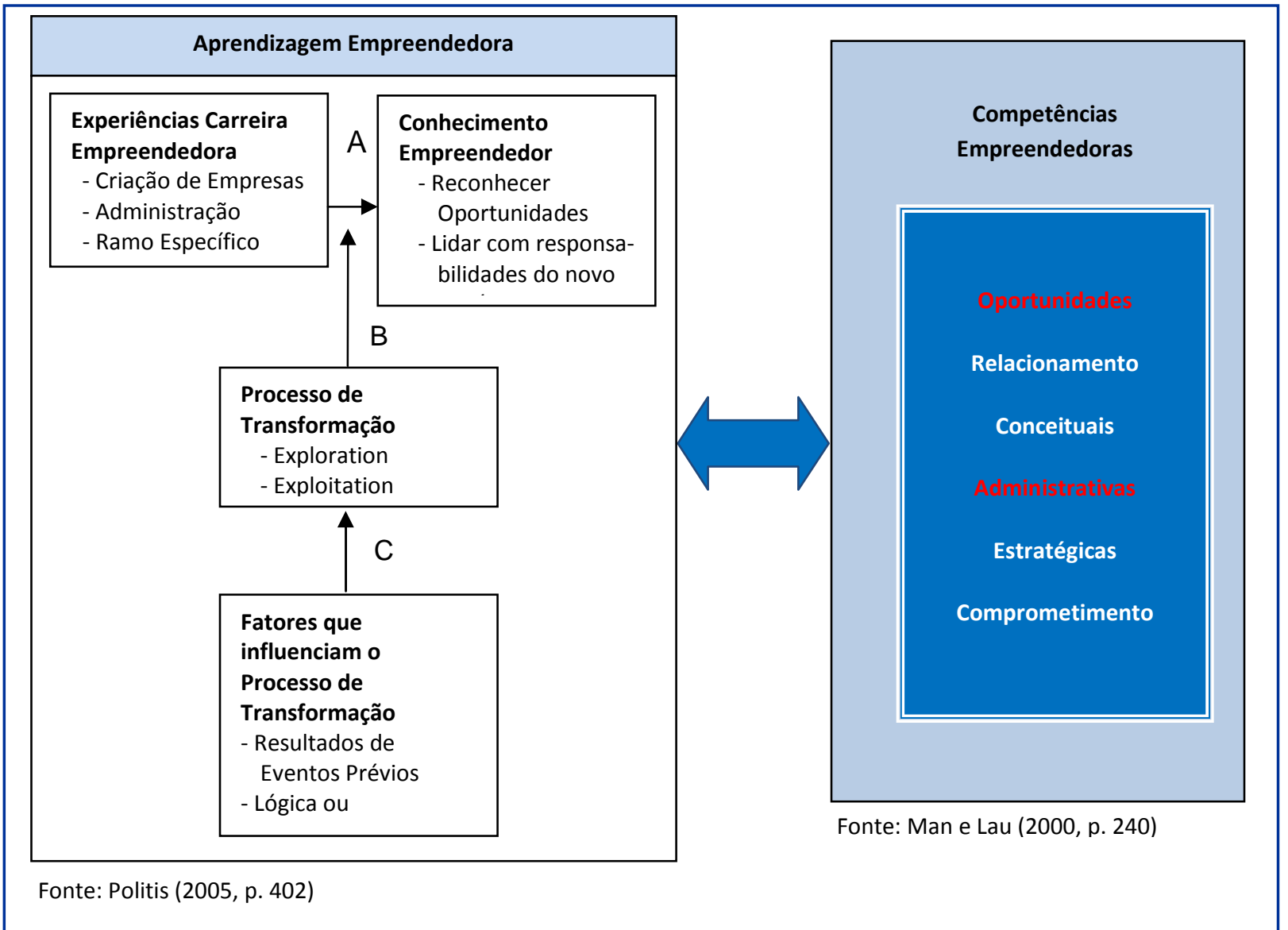

Fonte: Adaptado de Politis (2005) e Man e Lau (2000).

O desenvolvimento desse modelo integrador de teorias é o início do debate sobre a integração de aprendizagem empreendedora e competência empreendedora, pois ainda há que se fazer pesquisas empíricas que validem o construto, que é um desafio no campo teórico do empreendedorismo, embora já se tenha várias pesquisas sobre aprendizagem empreendedora e sobre competências empreendedoras separadamente.

\section{Considerações finais}

Não houve, em momento algum, qualquer pretensão descritiva no presente artigo, cujo objetivo foi o de apresentar os modelos de análise do processo de aprendizagem empreendedora de Rae (2004) e de Politis (2005) e integrar as teorias de aprendizagem empreendedora (POLITIS, 2005) e competências empreendedoras (MAN e LAU, 2000) por meio de um modelo conceitual de pesquisa. Pelo contrário, seu propósito é difundir a literatura existente e acender a discussão a esse respeito em nível nacional.

O modelo conceitual aqui apresentado, como tantos outros encontrados na literatura, consiste numa opção das autoras, ou seja, é uma escolha possível entre outras que podem ser construídas com base na literatura e que ainda precisa ser validada, aplicada. Portanto, em momento algum este modelo é considerado único ou o 
melhor, pois ele foi construído levando-se em conta os objetivos de uma pesquisa de escopo mais amplo que ainda será aplicada.

Conforme foi mencionado anteriormente na revisão da literatura, para explorar a inter-relação entre competências empreendedoras e aprendizagem empreendedora, os autores apresentam consenso na relevância de se utilizar a abordagem de aprendizagem experiencial, baseada na prática, no contexto e na ação, e de se investigar o conhecimento obtido. Da mesma forma, concordam com a necessidade de se realizarem pesquisas que privilegiem a história de vida dos empreendedores, suas carreiras e experiências, suas motivações e sua formação (RAE, 2004; POLITIS, 2005; PRIYANTO e SANDJOJO, 2005), possibilitando melhor compreensão do comportamento inovador do empreendedor.

Portanto, estudos desta natureza, podem não apenas contribuir para o desenvolvimento da literatura, mas também para a formulação de tecnologias sociais, ou seja, de estratégias de desenvolvimento, visando a reduzir problemas sociais como, por exemplo, o alto índice de mortalidade de PMEs no Brasil. A compreensão dos processos de aprendizagem do empreendedor e de como ele desenvolve suas competências podem subsidiar a formulação de políticas públicas e de tecnologias sociais para minimizar o impacto desses problemas, tanto em benefício do indivíduo empreendedor quanto do desenvolvimento econômico do país, como, por exemplo, oferta de microcrédito e de variados tipos de capacitação e treinamento voltados ao empreendedorismo.

\section{Referências}

ANTAL, A. B.; DIERKES, M; CHILD, J.; et al. Organizational learning and knowledge: Reflections on the dynamics of the field and challenges for the future. In: DIERKES, M. et al. (Orgs.) Handbook of organizational learning \& knowledge. Oxford: Oxford University Press. p. 921-939, 2001.

ANTONELLO, C. S. A metamorfose da aprendizagem organizacional: Uma revisão crítica. In: RUAS, R. L.; ANTONELLO, C. S.; BOFF, L. H. e colaboradores. Os novos horizontes da gestão: Aprendizagem organizacional e competências. Porto Alegre: Bookman, 2005. p. 12-33.

Aprendizagem na ação revisitada e sua relação com a noção de competência. Comportamento Organizacional e Gestão, v. 12, n. 2, p. 199-220, 2006.

BARINI FILHO, U. Transmissão da competência empreendedora: Um estudo de casos múltiplos. 2008. Tese (Doutorado) - Universidade de São Paulo, São Paulo, 2008.

BARON, R. A.; SHANE, S. A. Empreendedorismo: Uma visão do processo. São Paulo: Thomson Learning, 2007.

BITENCOURT, C. C. Gestão de competências e aprendizagem nas organizações. São Leopoldo/RS: Unisinos, 2005.

BOHNENBERGER, M. C.; SCHMIDT, S.; FREITAS, E. C. de. A influência da família na formação empreendedora. In: ENANPAD 2007. Anais... Rio de Janeiro/RJ.

BRUSH, C. et al. Doctoral education in the field of entrepreneurship. Journal of Management, v. 29, n. 3, p. 309-331, 2003.

BULL, I.; WILLARD, G. Towards a theory of entrepreneurship. Journal of Business Venturing, v. 8, n. 3, p. 183-196, 1993.

COOLEY, L. Entrepreneurship training and the strengthening of entrepreneurial performance. Final Report. Contract N. DAN-5314-C-00-3074-00. Washington: USAID, 1990. 
COPE, J. Toward a dynamic learning perspective of entrepreneurship. Entrepreneurship Theory and Practice, n. 29, v. 4 , p. $373-397,2005$.

CORBETT, A. C. Experiential learning within the process of opportunity identification and exploitation. Entrepreneurship Theory and Practice, p. 473-490, July 2005.

DEGEN, R. J. Empreendedor: Fundamentos da iniciativa empresarial. São Paulo: MacGraw-Hill, 1989.

DEMO, P. O futuro do trabalhador do futuro: Ótica estratégica do desenvolvimento humano. Genebra: OIT, 1994.

DIAS, T. R. F. V.; NARDELLI, P. M.; VILAS BOAS, A. A. Competências empreendedoras: Um estudo sobre os empreendedores ganhadores do prêmio TOP Empresarial. In: ENCONTRO DE ESTUDOS SOBRE EMPREENDEDORISMO E GESTÃO DE PEQUENAS EMPRESAS, 5, 2008. São Paulo. Anais... São Paulo/SP: EGEPE, 2008.

DORNELAS, J. C. A. Empreendedorismo na prática: Mitos e verdades do empreendedor de sucesso. Rio de Janeiro: Elsevier, 2007.

Empreendedorismo: Transformando idéias em negócios. 3. ed. Rio de Janeiro: Elsevier, 2008.

ESPEJO, M. M. S. B.; PREVIDELLI, J. J. Os grandes desafios e as estratégias do empreendedor no ensino superior privado. In: PREVIDELLI, J. J.; SELA, V. M. (Org.). Empreendedorismo e educação empreendedora. Maringá/Pr: Unicorpore, 2006. p. 21-52.

FERREIRA, J. M.; GIMENEZ, F. A. P.; RAMOS, S. C. Potencial empreendedor e liderança criativa: Um estudo com varejistas de materiais de construção da cidade de Curitiba/Pr. In: ENANPAD: 2005. Anais... Brasília/DF.

FEUERSCHÜTTE, S. G. Competências do empreendedor no setor hoteleiro: Caracterização e análise baseadas na metodologia da história oral [manuscritos]. 2006. Tese (Doutorado) - Universidade Federal de Santa Catarina, Florianópolis, 2006.

FEUERSCHÜTTE, S. G.; ALPERSTEDT, G. D. Empreendedorismo e competência: Um ensaio sobre a complementaridade e a convergência dos construtos. In: ENANPAD: 2008. Anais... Rio de Janeiro/RJ.

FEUERSCHÜTTE, S. G.; GODOI, C. K. Competências empreendedoras: Um estudo historiográfico no setor hoteleiro. In: ENANPAD: 2007. Anais... Rio de Janeiro/RJ.

FILION, L. J. O planejamento do seu sistema de aprendizagem empresarial: Identifique uma visão e avalie o seu sistema de relações. RAE, São Paulo, v. 31, n. 3, p. 63-71, jul./set.1991.

Empreendedorismo: Empreendedores e proprietários-gerentes de pequenos negócios. Revista de Administração, São Paulo, v. 34, n. 2, p. 5-28, abr./jun. 1999.

FLEURY, A.; FLEURY, M. T. L. Estratégias empresariais e formação de competências: Um quebra-cabeça caleidoscópico da indústria brasileira. 3. ed. São Paulo: Atlas, 2004.

FONSECA, F. R. B.; MELLO, S. C. B. de; PAIVA JR., F. G. de; et al. Competências empreendedoras como atributos geradores de valor: Um estudo de caso no setor de base tecnológica. In: ENCONTRO NACIONAL DE ESTUDOS DA ENGENHARIA DE PRODUÇÃO, 26, 2006, Fortaleza. Anais... Fortaleza/CE: ENEGEPE, 2006.

FREITAS, I. A. de.; BRANDÃO, H. P. Trilhas de aprendizagem como estratégias de TD\&E. In: BORGESANDRADE, J. E.; ABBAD, G. DA S.; MOURÃO, L. Treinamento, desenvolvimento e educação em organizações e trabalho: Fundamentos para a gestão de pessoas. Porto Alegre: Artmed, 2006. p. 97-113.

GARAVAN, T.; O'CINNEIDE, B. Entrepreneurship education and training programs: A review of and evaluation. Journal of European Industrial Training, v. 8, n. 8, p. 3-12, 1994. 
GARTNER, W. B. "Who is an entrepreneur?" Is the wrong question. Entrepreneurship Theory and Practice, v. 13, n. 4, p. 47-68, 1989.

GEM 2008. Global Entrepreneurship Monitor 2008 - Empreendedorismo no Brasil. Curitiba: IBPQ, 2009.

GHERARDI, S.; NICOLINI, D. Toward a social understanding of how people learn in organizations: The notion of situated curriculum. Management Learning, v. 29, n. 3, p. 273-297, 1998.

GRANOVETTER, M. Economic action and social structure: The problem of embeddedness. American Journal of Sociology, Chicago, v. 91, n. 3, p. 481-510, Nov. 1985.

GUIMARÃES, L. A experiência universitária norte-americana na formação de empreendedores: Contribuições das Universidades Saint Louis, Indiana e Babson College. 2002. Tese (Doutorado) - Escola de Administração de Empresas de São Paulo, Fundação Getúlio Vargas, São Paulo, 2002.

HARRISON, R. T.; LEITCH, C. M. Entrepreneurial learning: Researching the interface between learning and the entrepreneurial context. Entrepreneurship Theory and Practice, July 2005, p. 351-371.

HOLCOMB, T. R.; IRELAND, R. D; HOLMES JR., R. M. et al. Architecture of entrepreneurial learning: Exploring the link amons heuristics, knowledge, an action. Entrepreneurship Theory and Practice, p. 167-192, Jan. 2009.

HONMA, E. T. Competências empreendedoras: Estudo de casos múltiplos no setor hoteleiro em Curitiba. 2007. (Dissertação de Mestrado) - UFPR - Universidade Federal do Paraná, 2007.

KETS DE VRIES, M. F. R. Liderança na empresa: Como o comportamento dos líderes afeta a cultura interna. São Paulo: Atlas, 1997.

KIGGUNDU, M. Entrepreneurs and entrepreneurship in Africa: What is known and what needs to be done. Journal of Development Entrepreneurship, v. 7, n. 3, p. 239-258, 2002.

KOLB, D. A. Experiential learning: Experience as the source of learning and development. Englewood Cliffs, NJ: Prentice Hall, 1984.

LE BOTERF, G. Desenvolvendo a competência dos profissionais. Porto Alegre: Artmed, 2003.

LÉVESQUE, M.; MINNITI, M.; SHEPHERD, D. Entrepreneurs' decisions on timing of entry: Learning from participation and from the experiences of others. Entrepreneurship Theory and Practice, p. 547-570, Mar, 2009.

LÉVY-LEBOYER, C. Gestión de las competencias: Cómo analizarlas, cómo evaluarlas, cómo desarrollarlas. Barcelona: Ediciones Gestión, 2003.

LEZANA, A. G. R.; TONELLI, A. O comportamento do empreendedor. Florianópolis: Escola de Novos Empreendedores, 1998.

LONG, W. The meaning of entrepreneurship. American Journal of Small Business, v. 8, n. 2, p. 7-56, 1983.

MAMEDE, M. I. de B.; MOREIRA, M. Z. Perfil de competências empreendedoras dos investidores Portugueses e Brasileiros: Um estudo comparativo na rede hoteleira do Ceará. In: ENANPAD: 2005. Anais... Brasília/DF.

MAN, T. W. Y. Exploring the behavioural patterns of entrepreneurial learning: A competency approach. Education e Training, v. 48, n. 5, p. 309-321, 2006.

MAN, T. W. Y.; LAU, T. Entrepreneurial competencies of SME owner/managers in the Hong Kong services sector: A qualitative analysis. Journal of Enterprising Culture, v. 8, n. 3, p. 235-254, Sept. 2000.

MARCH, J. Exploration and exploration in organizational learning. Organization Science, v. 2, n. 1, 1991. 
MATTHEWS, C. H.; MOSER, S. B. A longitudinal investigation of the impact of family background and gender on interest in small firm ownership. Journal of Small Business Management, Apr. 1996.

McCLELLAND, D. C. A sociedade competitiva: Realização e progresso social. Rio de Janeiro: Expressão e Cultura, 1972.

MINNITI, M.; BYGRAVE, W. A dynamic modelo of entrepreneurial learning. Entrepreneurship Theory and Practice, p. 5-16, 2001.

MORAES, L. V. S.; HOELTGEBAUM, M. Um modelo para a análise do processo de aprendizagem de empreendedores. In: THIRD INTERNATIONAL CONFERENCE OF THE IBEROAMERICAN ACADEMY OF MANAGEMENT, 2003, São Paulo. Anais... São Paulo, 2003. v. 3. p. 1-20.

MORALES, S. A. Relação entre competências e tipos psicológicos junguianos. 2004.199 f. Tese (Doutorado) Programa de Pós-Graduação em Engenharia de Produção, UFSC, Florianópolis.

MORRISON, A. (Ed.). Entrepreneurship: An international perspective. Oxford: Butterworth-Heinemann, 1998.

MORRISON, A.; BERGIN-SEERS, S. Pro-Growth small businesses: Learning "Architecture". Journal of Management Development, v. 21, n. 5, p. 388-400, 2002.

MUELLER, S.; THOMAS, A. Culture and entrepreneurial potential: A nine country study of locus of control and innovativeness. Journal of Business Venturing, v. 16, p. 51-75, 2000.

PAIVA JÚNIOR, F. G.; GUERRA, J. R. F.; OLIVEIRA, M. A. F. de; et al. A contribuição das competências empreendedoras para a formação de dirigentes em sistemas de incubação. In: ENCONTRO NACIONAL DE ESTUDOS DA ENGENHARIA DE PRODUÇÃO, 26, 2006. Fortaleza. Anais... Fortaleza/CE: ENEGEPE, 2006.

PAIVA JÚNIOR, F. G.; LEÃO, A. L. M. de S.; MELLO, S. C. B. Competências empreendedoras em comportamentos de dirigentes de êxito socialmente reconhecido. In: ENCONTRO DA ASSOCIAÇÃO NACIONAL DOS PROGRAMAS DE PÓS-GRADUAÇÃO EM ADMINISTRAÇÃO, 27, 2003, Atibaia. Anais... Atibaia/SP: ANPAD, 2003.

PEREIRA, L. B. Processo empreendedor de spin-offs universitárias: Principais fatores determinantes. 2007. Dissertação (Mestrado) - Universidade Federal de Minas Gerais, 2007.

PITTAWAY, L.; COPE, J. Simulating entrepreneurial learning: Integrating experiential and collaborative approaches to learning. Management Learning, v. 38, n. 2, p. 211-233, 2007.

POLITIS, D. The process of entrepreneurial learning: A conceptual framework. Entrepreneurship Theory and Practice, p. 399-424, July 2005.

Does prior start-up experience matter for entrepreneurs' learning? A comparison between novice and habitual entrepreneurs. Journal of Small Business and Enterprise Development, v. 15, n. 3, p. 472-489, 2008.

POLITIS, D.; GABRIELSSON, J. Exploring the role of experience in the process $f$ entrepreneurial learning. Lund Institute of Economic Research. Working Paper Series, 2005.

Entrepreneurial decision making: Examining preferences for causal and effectual reasoning in the new venture creation process. Lund Institute of Economic Research. Working Paper Series, 2006.

PRIYANTO, S. H.; SANDJOJO, I. Relationship between entrepreneurial learning, entrepreneurial competencies and venture success: Empirical study on SMEs. International Journal Entrepreneurship and Innovation Management, v. 5, n. $5 / 6$, p. $454-467,2005$.

RAE, D. Entrepreneurial learning: A practical model from the creative industries. Education + Training, v. 46, n. 8/9, p. 492-500, 2004. 
Entrepreneurial learning: A narrative-based conceptual model. Journal of Small Business and Enterprise Development, v. 12, n. 2, p. 323-335, 2005.

Entrepreneurial learning: A conceptual framework for technology-based enterprise. Technology Analysis \& Strategic Management, v. 18, n. 1, p. 39-56, 2006.

RAE, D.; CARSWELL, M. Using a life-story approach in researching entrepreneurial learning: The development of a conceptual model and its implications in the design of learning experiences. Education \& Training, v. 42, n. 4/5, p. 220-227, 2000.

RAVASI, D.; TURATI, C. Exploring entrepreneurial learning: A comparative study of technology development projects. Journal of Business Venturing, v. 20, p. 137-164, 2005.

RUAS, R. Gestão por competências: Uma contribuição à estratégia das organizações. In: RUAS, R.; ANTONELLO, C. S.; BOFF, L. H. (Colab.). Os novos horizontes da gestão: A aprendizagem organizacional e competências. Porto Alegre: Bookman, 2005. p. 34-54.

SARASVATHY, S. D. Causation and effectuation: Toward a theoretical shift from economic inevitability to entrepreneurial contingency. Academy of Management Review, v. 26, n. 2, p. 243-288, 2001.

SCHEIN, E. Organizational Culture and Leadership. San Francisco: Jossey-Bass Publishers, 1985.

SCHERER, R. F.; ADAMS, J. A developing entrepreneurial behaviors: A social learning theory perspective. Journal of Organizational Change Management, 1998.

SCHUMPETER, J. A. Teoria do desenvolvimento econômico. São Paulo: Abril Cultural, 1982.

SHANE, S.; VENKATARAMAN, S. The promise of entrepreneurship as a field of research. The Academy of Management Review, v. 25, n. 1, p. 217-226, Jan. 2000.

SNELL, R.; LAU, A. Exploring local competences salient for expanding small business. Journal of Management Development, v. 13, n. 4, 1994.

STEVENSON, H. H.; JARILLO, J. C. A paradigm of entrepreneurship: Entrepreneurial management. Strategic Management Journal, v. 11, n. 4, p. 17-27, 1990.

SWIERINGA, J.; WIERDSMA, A. La organización que aprende. Buenos Aires: 1992.

TAYLOR, D. W.; THORPE, R. Entrepreneurial learning: A process of co-participation. Journal of Small Business and Enterprise Development, v. 11, n. 2, p. 203-211, 2004.

VENKATARAMAN, S. The distinctive domain of entrepreneurship research. In: KATZ, J.; BROCKHAUS. R. Advances in Entrepreneurship, Firm Emergence and Growth, v. 3, p. 119-138. Greenwich, CT: JAI Press, 1997.

WEBER, M. A ética protestante e o espírito do capitalismo. São Paulo: Pioneira, 1989.

WEICK, K. E.; WESTLEY, F. Organizational learning: affirm an oxymoron. In: GLEGG, S. et al. (Orgs.). Handbook of organizational studies. Londres: Sage. p. 440-458, 1996.

ZARIFIAN, P. Objetivo competência: Por uma nova lógica. São Paulo: Atlas, 2001. 